\title{
Polio eradication efforts in regions of geopolitical strife: the Boko Haram threat to efforts in sub-Saharan Africa.
}

\author{
Jean Joel R. Bigna ${ }^{1,2}$
}

1. Department of Epidemiology and Public Health, Centre Pasteur of Cameroon, Yaoundé, Cameroon.

2. Bordeaux School of Public Health, University of Bordeaux, Bordeaux, France.

\begin{abstract}
The World Health Organization aims to eradicate wild poliovirus worldwide by the end of 2018. Cameroon and Nigeria, neighboring countries, have been affected by the terrorist and militant activities of the Islamist sect Boko Haram. Impacted regions are mainly the far North of Cameroon and Northern Nigeria. Targets of Boko Haram aggression in these zones include violence against polio workers, disruption of polio immunization campaigns, with consequent reduced access to health care and immunization. In addition to this significant problem, Northern Nigeria has historically seen rejection of polio virus vaccine initiatives. It remains to know how health systems can continue operations against polio in areas where Boko Haram operates. If appropriate measures are not urgently taken, it will be not possible to meet the 2018 goal of polio virus eradication. The response should include specialized immunization activities in conflict zones, will engagement of leaders. Countries should also explore immunization activities by soldiers and military personnel.
\end{abstract}

Keywords: Boko Haram, terrorism, polio, polio virus, wild polio virus, vaccination, immunization, Nigeria, Cameroon.

DOI: http://dx.doi.org/10.4314/ahs.v16i2.28

Cite as: Bigna JJR. Polio eradication efforts in regions of geopolitical strife: the Boko Haram threat to efforts in Sub-Saharan Africa. Afri Health Sci 2016;16(2): 584-587. http://dx.doi.org/10.4314/abs.v16i2.28

\section{Background}

The human poliovirus, an enterovirus, is the causative agent of polio. There are three serotypes of wild poliovirus (WPV) - type 1 , type 2 , and type $3^{1}$. Polio is highly infective and mainly affects children under 5 years old. Irreversible paralytic polio occurs in $1 / 200$ poliovirus infections. Among those paralyzed, $5 \%$ to $10 \%$ die once breathing muscles become compromised ${ }^{2}$. Polio cases have decreased by over $99 \%$ since 1988, from an estimated 350,000 cases then, to 416 reported cases in 2013. The striking reduction is the result of the global effort, launched in 1988, to eradicate the disease ${ }^{2}$. There is no

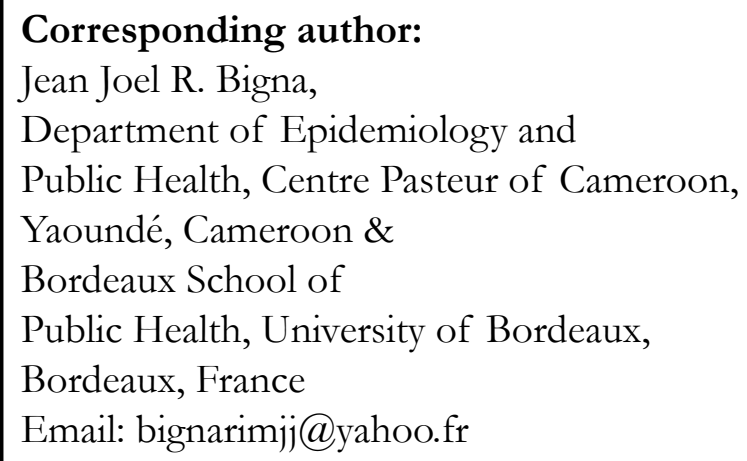


vaccine, scheduled for April 2016 ${ }^{7}$. In addition, there was case of type 2 WPV recovered from human cases of polio illness in 2014 and in 2015,3. The aim of this paper is to present how Boko Haram activities may impact the plan to eliminate polio and to propose some solutions to avoid outbreaks of polio during and after armed conflicts.

\section{What is the problem?}

Cameroon and Nigeria have been countries affected by the terrorist and war activities of the Islamist sect Boko Haram, specifically in the far North region of Cameroon and Adamawa, Borno and Yobe states in Northern Nigeria. The Borno state of Nigeria and the far North region of Cameroon share a border. The effects of Boko Haram in these zones include violence against polio workers, disruption of immunization campaigns, and reduced access to health care and to immunization ${ }^{8,9}$. Targeted killing of healthcare workers, destruction of healthcare facilities, and displacement of huge populations have been reported ${ }^{10}$. In addition, Northern Nigeria has historically been an area where polio virus vaccination efforts have met with resistance as individuals refuse immunization refusal $^{11-14}$. Erroneous beliefs by some populations in Nigeria and Cameroon link polio vaccination to sterility in women ${ }^{15}$.

WPV circulates in sub-Saharan Cameroon and Nigeria: Cameroon is an exporter of the virus ${ }^{6}$ and Nigeria remains an endemic transmission country for polio virus in $2014^{3}$. These two neighboring countries share a long porous boundary, with a length of about $1690 \mathrm{~km}$. The last cases of poliomyelitis were reported in Cameroon and Nigeria on 9 and 24 July 2014 respectively ${ }^{6,16}$. The WHO has called for these countries to eradicate WPV and prevent its spread ${ }^{6,17}$. The commitment of both countries to eradicate it and stop its spread is clear, given the time that has now elapsed since the last reported cases of Polio. For example, in Nigeria only six WPV cases were reported in the first nine months of 2014 as compared with 49 reported cases during the same period in $2013^{18}$.

One must be careful in reviewing statistics, which may underestimate the true amount of virus in circulation. Cameroon is a country where the virus can circulate silently, particularly given an orphan polio virus strain found in 2013, and given a weak surveillance system for acute flaccid paralysis (AFP) surveillance system when submitted stool specimens are inadequate for viral identification ${ }^{6,19}$.
The quality of AFP surveillance is measured by two principal indicators. The first is the non-polio AFP rate (i.e., the number of cases of non-polio AFP in children aged $<15$ years per 100,000 person-years). This indicator is met if the non-polio AFP rate is $\geq 2$, which is considered sufficiently sensitive to identify cases from circulating polio virus. ${ }^{20}$ The second indicator is the percentage of stool specimens considered adequate (i.e., collection within 14 days of paralysis onset, 24-48 hours apart, and arrival at the laboratory in "good" condition). To meet this indicator, adequate stool specimens should be collected for $\geq 80 \%$ of AFP cases, which shows that surveillance in the area can effectively identify WPV and VDPV among individuals with AFP. $^{20}$ In 2014, all states in Nigeria had non polio AFP rate $>2$ per 100,000 persons aged $<15$ years and specimen adequacy $>80 \%$; - in Cameroon, Far North region had non polio AFP rate $>2$ per 100,000 persons aged $<15$ years and specimen adequacy $<80 \%$ 19. The quality of the specimen stool in far North region of Cameroon remained therefore low. Efforts should be made in this direction to improve its quality.

It remains to know how health systems could be most efficient in their operations against polio in areas where Boko Haram operates with terrorist activities. If measures are not urgently taken, it will be not possible to eradicate the polio virus by 2018 .

\section{What are possible solutions? Vaccination activities}

It is necessary to implement special immunization activities for displaced populations and continuously increase and improve them when they are in place. This could be done for refugees in communities where populations are displaced. Vaccination against polio can also be performed in peri-war zones during the displacement. After cessation of armed conflicts, one could carry out special immunization activities. During war, soldiers and military personnel can be trained to give oral polio vaccine.

\section{Engagement of stakeholders in the fight against wild polio virus}

The commitment of stakeholders all levels to promote vaccination against polio, including health, religious, political, administrative, community and traditional authorities is also necessary. The political authorities can actively engage to secure financial resources and material from non-governmental organizations and international organizations. The health system could contribute by train- 
ing soldiers on how to administer polio vaccine. All these authorities could contribute to the communication plan and the introduction of trained vaccinators into the communities to avoid refusals of immunization. In addition to delivery of water, education material, food, and other supplies in war torn zones and to vaccination of populations in war zones, one could promote a "Peace Day".

This is to convince all parties involved to cease hostilities to allow children and adults access to care. This has already been used with success in Afghanistan, Southern Sudan and Somalia. Religious and traditional authorities could help for the communication between all parties with purpose to conduct vaccination. But with Boko Haram, it is not sure that this will is feasible, given their ruthlessness and brutality. It is why it is important that in periods of apparent lull, some soldiers trained for vaccination can immunize populations. As in war zones health services are weak and sometimes non-existent, the trained soldiers could then administer the vaccine to people who have not moved out of war areas or populations being moved to the periphery areas wars. It does not require special skills to administer one dose per os or by injection of a vaccine. "Money is the nerve of war", so, going to war against wild poliovirus will require sufficient funding to destroy it. Partners of these countries should assist them in the implementation of these activities; regarding the expenses that the war against Boko Haram consumed. The same method could be considered for other exporters WPV countries where there are wars, including Pakistan, Syria and $\operatorname{Iraq}^{3,6}$.

\section{Conclusion}

Due the insecurity and violence caused by Boko Haram, it is necessary for these two countries, Cameroon and Nigeria, in collaboration with their partners, prepare a response plan to prevent an outbreak of polio cases during and after the war. Otherwise, the eradication of WPV will not be effective at the end 2018. This response would require two main areas: special immunization activities within war area and fully engagement of the leaders. Countries can also explore immunization activities by soldiers.

\section{List of abbreviations}

AFP: acute flaccid paralysis

VDPV: vaccine derived poliovirus
WHO: World Health Organization

WPV: wild poliovirus

\section{Competing interests}

The author declares no competing interest.

\section{Authors' contributions}

JJRB conceived, conducted literature search, drafted the manuscript, and approved the final version to publish.

Acknowledgements

The author thanks Claudia S. Plottel, MD, MSc for editorial assistance in preparation of the final version of the manuscript.

\section{References}

1. World Health Organization. Poliomyelitis: World Health Organization; 2015 [cited 2015 Apr 30]. Available from:http://www.who.int/biologicals/areas/vaccines/ poliomyelitis/en/.

2. World Health Organization. Poliomyelitis: Fact sheet N¹14: World Health Organization; 2014 [cited 2015 Apr 30]. Available from:http://www.who.int/mediacentre/ factsheets/fs114/en/.

3. The Global Polio Eradication Initiative. Polio News: December 2014: The Global Polio Eradication Initiative; 2014 [cited 2015 Jan 30]. Available from:http://www.polioeradication.org/Portals/0/Document/Media/Newsletter/PN201413_EN.pdf.

4. The Global Polio Eradication Initiative. Polio news: April 2015: The Global Polio Eradication Initiative; 2015 [cited 2015 Apr 30]. Available from:http://www.polioeradication.org/Portals/0/Document/Media/Newsletter/PN201504_EN.pdf.

5. CDC. Updates on CDC's Polio Eradication Efforts Atlanta, USA: CDC; 2015 [updated Dec 11, 2015; cited 2016 Jan 15].

6. World Health Organization. Poliomyelitis: 136th session - 2015 Jan 15: World Health Organization; 2015 [cited 2015 Jan 16]. Available from:http://apps.who.int/gb/ ebwha/pdf_files/EB136/B136_21-en.pdf.

7. World Health Organization. Progress against the polio eradication and endgame strategic plan 2013-2018. World Health Organization, 2014.

8. Smith D. Polio workers in Nigeria shot dead: the guardian; 2013 [cited 2015 May 02]. Available from: http:// www.theguardian.com/world/2013/feb/08/polio-workers-nigeria-shot-dead. 
9. Omole O, Welye H, Abimbola S. Boko Haram insurgency: implications for public health. Lancet. 2015;385(9972):941.

10. Hamisu AW, Johnson TM, Craig K, Mkanda P, Banda $\mathrm{R}$, Tegegne SG, et al. Strategies for Improving Polio Surveillance Performance in the Security-Challenged Nigerian States of Adamawa, Borno, and Yobe During 20092014. The Journal of infectious diseases. 2015.

11. Michael CA, Ogbuanu IU, Storms AD, Ohuabunwo CJ, Corkum M, Ashenafi S, et al. An assessment of the reasons for oral poliovirus vaccine refusals in northern Nigeria. The Journal of infectious diseases. 2014;210 Suppl 1:S125-30.

12. Mangal TD, Aylward RB, Mwanza M, Gasasira A, Abanida E, Pate MA, et al. Key issues in the persistence of poliomyelitis in Nigeria: a case-control study. The Lancet Global health. 2014;2(2):e90-7.

13. Chen $\mathrm{C}$. Rebellion against the polio vaccine in Nigeria: implications for humanitarian policy. African Health Sciences. 2004;4(3):205-7.

14. Ghinai I, Willott C, Dadari I, Larson HJ. Listening to the rumours: what the northern Nigeria polio vaccine boycott can tell us ten years on. Global Public Health. 2013;8(10):1138-50.
15. Callaway E. Smart shots bring Nigeria to brink of polio eradication. Nature. 2015;523(7560):263-4.

16. World Health Organization. Poliovirus in Cameroon - update: World Health Organization; 2014 [cited 2015 Jan 31]. Available from:http://www.who.int/csr/ don/2014_09_06_polio/en/.

17. World Health Organization. WHO statement on the meeting of the International Health Regulations Emergency Committee concerning the international spread of wild poliovirus: World Health Organization; 2014 [cited 2015 Jan 30]. Available from: http://who.int/mediacentre/news/statements/2014/polio-20140505/en/.

18. Etsano A, Gunnala R, Shuaib F, Damisa E, Mkanda P, Banda R, et al. Progress toward poliomyelitis eradication-Nigeria, January 2013-September 2014. MMWR Morbidity and mortality weekly report. 2014;63(46):1059-63. 19. PorterKA, Diop OM, Burns CC, Tangermann RH, Wassilak SG. Tracking progress toward polio eradication - worldwide, 2013-2014. MMWR Morbidity and mortality weekly report. 2015;64(15):415-20.

20. Levitt A, Diop OM, Tangermann RH, Paladin F, Kamgang JB, Burns CC, et al. Surveillance systems to track progress toward global polio eradication - worldwide, 2012-2013. MMWR Morbidity and mortality weekly report. 2014;63(16):356-61. 